\title{
Conciencia: según el Concilio Vaticano Il y según S. S. Francisco ¿continuidad o innovación?"
}

\author{
Juan David Ospina Ospina **
}

Recibido: 03 de octubre 2014 • Aprobado: 28 de noviembre 2014

\author{
"La conciencia es el primero \\ de todos los vicarios de Cristo." \\ Newman \\ Carta al Duque de Norfolk, 5.
}

\section{Resumen}

Son muchos los derechos que por nuestra condición ontológica e inherente de seres humanos nos son propios, tales como el derecho a la vida, a una familia, a un techo, al agua, entre otros. Pero sin duda, el derecho más importante, y que quizás cobija los derechos antes mencionados, es el derecho a una vida digna. Innegablemente el derecho a una vida digna responde en proporción directa a la dignidad de la persona; es decir, se vive dignamente, en tanto se respete y se propenda por la dignidad de la persona. Pero, ¿qué le es propio a la dignidad del Ser humano? Al igual que los derechos inherentes a nuestra condición de seres humanos, son muchos los factores que determinan y exaltan la dignidad del Ser humano; pero nada la es tan propio y fundamental como el actuar según la propia conciencia. La presente investigación pretende exponer de manera sistemática y sintética la doctrina y el desarrollo teológico en el magisterio conciliar (Concilio Vaticano II) sobre la conciencia,

*Este artículo es producto de la investigación del autor.

** Teólogo de la Universidad Santo Tomás. Fraile dominico del Convento Lacordaire, Medellín, Colombia. Correo electrónico: jdleonospina@hotmail.com. 
su importancia e influjo en la vida del creyente, en comparación con su desarrollo en el magisterio expuesto por SS. Francisco, con el propósito de vislumbrar diferencias, innovación o continuidad respecto del concepto de conciencia y su importancia en la vida del creyente.

Palabras clave: Conciencia, Formación de la conciencia, profesión de fe, Teología, Discernimiento, Voz de Dios, Moral.

\title{
Awareness: According to Vatican II and HH Pope Francis continuity or innovation?
}

\begin{abstract}
Many are the rights that for our ontological condition and inherent to human beings are our own, such as right to life, a family, roof, water among others. But undoubtedly, the most important right, and which perhaps covers all the aforementioned, is the right to a decent life. Undeniably the right to a decent life responds directly to the dignity of the person; i.e., we live in dignity, while we respect and tend for the dignity of the person. But, what is inherent to the dignity of the human Being? Like all the rights inherent to our condition of human beings, many are the factors that determine and exalt the dignity of the human Being; but nothing is as inherent and fundamental as acting according to our own conscious.

This research intends to present in a systematical and concise manner the doctrine and theological development in the conciliar magisterium (Vatican II) about the conscience, its importance and influence in the life of the believer, compared with its development in the teachings expounded by HH Pope Francis, in order to discern the differences, innovation or continuity regarding the concept of conscious and its importance in the life of the believer.
\end{abstract}

Keywords: Conscience, Formation of consciousness, profession of faith, Theology, Discernment, Voice of God, Moral

\section{Conscience: Selon le Concile Vatican II et selon S.S. Francisco ¿continuité ou innovation?}

De nombreux droits inhérents aux êtres humains et du à notre condition ontologique, ne nous appartiennent pas, tes que le droit à la vie, à une famille, à un toit, à l'eau, entre autres. Mais sans aucun doute, le droit le plus important, et qui comprend les droits 
ci-dessus mentionnés, est le droit à une vie digne. Incontestablement le droit à une vie digne est proportionnellement direct à la dignité de la personne; c'est à dire qu'on vit une vie digne dans la mesure où on puisse promouvoir la dignité de la personne. Mais ¿ qu'est il inhérent à la dignité de l'être humain? De la même façon que les droits inhérents à notre condition d'êtres humains, beaucoup de facteurs déterminent et exaltent la condition de $l^{\prime}$ Etre humain. Mais rien ne lui est aussi propre et fondamental que d'agir selon sa propre conscience.

Cette recherche prétend exposer de manière systématique et synthétique, la doctrine et le développement théologique au sein du magistère du concile (Concile Vatican II) sur la conscience, son importante et influence dans la vie du croyant, en comparaison avec son développement au sein du magistère exposé par S.S. Francisco, dans le but d'entrevoir des différences, innovation ou continuité à l'égard de du concept de conscience et son importance dans la vie du croyant.

Mots-Clés: Conscience, Formation de la conscience, profession de foi, Théologie, Discernement, Voix de Dieu, Morale

\section{El Concilio Vaticano II y la conciencia}

La conciencia, como categoría teológica, es para la vida del creyente, el "lugar" de encuentro íntimo consigo mismo y con Dios. Es el "lugar" dónde el individuo y sólo él puede llevar a cabo la valoración ética y moral de su ser, de su comportamiento, de sus actos y decisiones y darle así sentido a su ser de persona y de creyente. Es en la conciencia el único lugar donde el individuo creyente analiza, valora y reflexiona sobre la naturaleza, intención y consecuencias de sus actos y decisiones respecto de los demás y respecto a su relación con Dios. Por tal motivo, es en la conciencia donde, a partir de la moralidad cristiana en ella formada, se constituye el vínculo personal con Dios, que en otras palabras es la forma o perspectiva de percibir qué o quién es Dios, de comprender su mensaje y asumir una postura o comportamiento ante el mundo y sus desafíos.

Es por todo lo anterior, que la conciencia, como categoría teológica, es de suma importancia para la vida del creyente, y por tanto, a raíz de la misión de la Iglesia de ser Madre y Maestra de los hijos de Dios, a la vez que está constituida para ser la custodia del pueblo de Dios, está en la tarea de procurar la formación de la conciencia de los creyentes, para que sea el mensaje real y auténtico de Dios -el contenido en la Sagrada Escritura, la Tradición y el Magisterio- el que modele la vida del creyente, y sea la conciencia el lugar de encuentro íntimo con Dios, dónde el creyente sea conducido a gozar de la salvación de Dios dispensada en 
la Iglesia y por la Iglesia a través de la liturgia (los sacramentos). Así pues, es grande el esfuerzo que la Iglesia católica invierte en su magisterio para llevar al creyente a discernir sobre la importancia de una sana y recta conciencia, a la vez que ésta, a mi modo de ver, representa para la Iglesia "un lugar teológico", puesto que es un "lugar" privilegiado de encuentro y de constancia de la acción de Dios en la vida personal, así como el lugar donde se discierne la voluntad de Dios, tal y como lo dice el Apóstol de los gentiles: "transformaos mediante la renovación de vuestras mentes, de forma que podáis distinguir cuál es la voluntad de Dios: lo bueno, lo agradable, lo perfecto" (Rm 12, 2).

Por otra parte, siendo el Concilio Vaticano II (CV II) el encuentro eclesial más importante de los últimos tiempos, es indispensable abordarlo para discernir en sus disertaciones teológicas el magisterio que brinda a la Iglesia toda sobre el tema de la conciencia. Empero, pudiendo llevar a cabo el ejercicio de rastrear todos los documentos conciliares para identificar y resaltar lo concerniente a la conciencia, la tarea y el esfuerzo estará centrado en la constitución Gaudium et Spes (GS) respecto a lo que de la conciencia trata. La razón de tal empresa, es que es ésta la constitución pastoral sobre la iglesia y el mundo de hoy, y por tanto, aborda con mayores luces la el valor y la importancia de la conciencia tanto para el mundo como para el ejercicio pastoral de la Iglesia. Así también, siendo el Catecismo de la Iglesia Católica (CEC) el compendio del magisterio pos conciliar, será pasó obligado en el presente artículo.

\section{Concilio vaticano II $^{1}$}

Es evidente a la lectura dedicada y pausada de los documentos conciliares, que en lo referente a la conciencia, la reflexión teológica concerniente no constituyó un tratado sistemático, por lo cual, las referencias textuales al tema están dispersas en varios documentos del CV II. Por tal motivo, ciertos teólogos consideran que la reflexión teológica respeto de la conciencia es pobre y vaga, y es un tema con un amplio y vasto tema de discusión teológica; así lo expresa el teólogo Rafael Braun": "la reflexión sobre la conciencia no parece haber sido una tarea central en

1 XXI Concilio (encuentro de todos los obispos de la Iglesia católica) ecuménico de la Iglesia Católica. Fue convocado por el Papa Juan XXIII en 1962 y clausurado por el Papa Paulo VI en 1965.

2 Sacerdote de la Iglesia Católica, nacido en Buenos Aires en 1935, es doctor en Filosofía por la Universidad de Lovaina (Bélgica) y licenciado en teología por la Universidad Católica Argentina.

\section{Universidad Santo Tomás, Facultad de Teología}


la labor conciliar, y cuando el tema es abordado, la mayoría de las veces se lo hace aplicando las categorías de la filosofía moral. La reflexión teológica propiamente es escasa." (Braun, 1969, p. 41)

A pesar de la falta de una reflexión sistemática y de un documento que contenga en totalidad la reflexión teológica sobre la conciencia en el CV II, el concilio centró la mayor parte de las disertaciones teológicas sobre la conciencia en dos documentos, a saber, la constitución Pastoral Gaudium et Spes ${ }^{3}$ (GS) y la declaración Dignitatis Humanae ${ }^{4}(\mathrm{DH})$, de los cuales, el primer documento representa en densidad y profundidad el mayor abordaje teológico hecho por el concilio sobre el tema de la conciencia.

Por otra parte, es evidente que el abordaje que en su mayoría el concilio hace respecto de la conciencia, son disertaciones teológicas de la conciencia en tanto ésta como lugar de la reflexión moral, como punto de partida del comportamiento moral, razón por la cual la categoría más usada y explicita en lo referente a la conciencia es la de "conciencia moral." En palabras del teólogo Rafael Braun, según el cual el concilio afirma que las facultades intelectuales propias del hombre (uso de la razón) que posibilitan el conocimiento de la verdad y direccionan sus acciones al bien, constituyen al ser como un ser moral; así pues, siguiendo el concilio, Braun afirma que "esta dimensión moral es una estructura inherente a la naturaleza del hombre" (Braun, 1969, p. 42) y en tanto el Ser sea un Ser racional, éste inscribe su comportamiento en la esfera de la obligación moral. En conclusión, ya que la conciencia moral se desprende de la facultad racional del hombre y de su inherente búsqueda de la verdad, y estas facultades a la vez son propias de la naturaleza humana, se concluye entonces que la conciencia moral es propia también de la naturaleza humana, de ahí la obligación moral.

Por otra parte, en líneas de la declaración $D H$ se expresa que "todos los hombres, conforme a su dignidad, por ser personas, es decir, dotados de razón y voluntad libre (...) tienen la obligación moral de buscar la verdad (...). Están obligados asimismo, a adherirse a la verdad conocida y a ordenar toda su vida según las exigencias de la verdad." (DH, p. 423). De este modo, según lo expone Braun siguiendo esta la declaración conciliar, el resultado de la búsqueda de la verdad y de la posterior adhesión a ella, es el proceso por el cual el ser logra la formación prudente de la conciencia, consiguiendo así la emisión de juicios

3 Constitución Pastoral sobre la Iglesia en el mundo actual, promulgada por el Papa Pablo VI el 7 de Diciembre de 1965.

4 Declaración sobre la libertad religiosa promulgada el 7 de Septiembre de 1965 por Pablo VI. 
rectos y verdaderos. Así pues, es de apremiante importancia resaltar, a modo de conclusión del presente párrafo, que si bien es cierto la razón posee una vital importancia en el acceso natural a la verdad, también lo es el hecho de que es en la conciencia donde la verdad se "encarna", se hace acto y estilo de vida; la conciencia es el lugar donde la verdad conocida se hace verdad vivida. El ser a través de la razón conoce y percibe el orden propio del cosmos y su relación con el mundo que lo rodea, pero es en la conciencia donde tal conocimiento se "descodifica" y se descubre en el orden la manifestación de Dios, y se descubre así mismo como creatura en relación con la creación y como parte de ella, como ser finito y temporal.

Por otra parte, ya que la declaración DH pone de manifiesto la realidad creatural del ser, consignando en sus líneas la verdad sobre el ser como salido de la mano de Dios en la creación, Dignitatis Humanae evidencia que ya que el hombre no se da el ser a sí mismo, sino que depende ontológicamente de Dios, así también, la ley moral el ser no se la da así mismo, sino que le es dada por Dios. El ser por su razón conoce la ley natural, pero es en la conciencia donde el hombre descubre en ella la voluntad de Dios, voluntad a la que ha de ser obediente; por tanto, la ley natural, como ley querida por Dios para comunicar la verdad y la naturaleza del hombre en relación con la verdad de sí mismo, se transforma en máxima del comportamiento moral, de conciencia moral, para hacer el bien y evitar el mal, cuando es asimilada por una conciencia formada en la búsqueda de la verdad, que no es otra que la verdad de Dios y de su voluntad; así pues, es en la conciencia donde se descubre la voluntad querida por Dios.

\section{Constitucion Gaudium et Spes}

En la Constitución GS se recogen y se profundizan muchas de las disertaciones teológicas presentes en la declaración DH. Así por ejemplo, cuando se aborda el tema de la conciencia, mayoritariamente se hace al referirse a la moral, esto es, a la conciencia moral. Del mismo modo, se hace presente en la teología de la GS la realidad del ser como creatura hecha a imagen y semejanza de Dios, condición ontológica de dependencia de los hombres a Dios, a la vez que resalta la vitalidad del aspecto antropológico en la reflexión moral, teniendo como punto de partida un enfoque personalista. 
La constitución pastoral hace seguimiento de la DH y en continuidad con ésta, según Gustavo A. Morales López ${ }^{5}$, afirma que el hombre es un ser moral y ético, y tal facultad moral se deriva de la conciencia, de este modo, "la conciencia representa el centro de la vida moral del hombre." (2011, p. 101.)

Es de notarse, sin embargo, que a pesar de ser GS el texto conciliar que más recoge en profundidad la reflexión teológica en cuanto a la conciencia se refiere, tal reflexión puede señalarse explicitada en un único numeral, a saber el numeral 16 de la GS, en donde se lee:

"16. En lo más profundo de su conciencia descubre el hombre la existencia de una ley que él no se dicta a sí mismo, pero a la cual debe obedecer, y cuya voz resuena, cuando es necesario, en los oídos de su corazón, advirtiéndole que debe amar y practicar el bien y que debe evitar el mal: haz esto, evita aquello. Porque el hombre tiene una ley escrita por Dios en su corazón, en cuya obediencia consiste la dignidad humana y por la cual será juzgado personalmente. La conciencia es el núcleo más secreto y el sagrario del hombre, en el que éste se siente a solas con Dios, cuya voz resuena en el recinto más íntimo de aquélla. Es la conciencia la que de modo admirable da a conocer esa ley cuyo cumplimiento consiste en el amor de Dios y del prójimo. La fidelidad a esta conciencia une a los cristianos con los demás hombres para buscar la verdad y resolver con acierto los numerosos problemas morales que se presentan al individuo y a la sociedad. Cuanto mayor es el predominio de la recta conciencia, tanto mayor seguridad tienen las personas y las sociedades para apartarse del ciego capricho y para someterse a las normas objetivas de la moralidad. No rara vez, sin embargo, ocurre que yerra la conciencia por ignorancia invencible, sin que ello suponga la pérdida de su dignidad. Cosa que no puede afirmarse cuando el hombre se despreocupa de buscar la verdad y el bien y la conciencia se va progresivamente entenebreciendo por el hábito del pecado."

La razón por la cual tan solo en un numeral de la GS se expone explícitamente el tema de la conciencia, es debido a que siendo esta constitución un documento pastoral sobre la Iglesia y la relación de ésta con el mundo, son diversos los temas por ella tratados y abordados. En cuanto a la composición de GS,

5 Docente del Instituto de Ciencias Religiosas, Pontificia Universidad Católica de Valparaíso, Chile. 
este documento se divide en dos secciones, la primera refiere a problemáticas y realidades antropológicas; según Morales López, esta primera sección aborda los temas sobre "el hombre, sus preguntas más hondas, el misterio que entraña, los cambios que enfrenta, la dignidad de su persona, su conciencia y su libertad, etc." (Morales, 2011, p. 102) Por otra parte, la segunda sección refiere a problemáticas más propias de la humanidad en general. De este modo, debido a que son bastantes y de profunda complejidad los problemas relacionados con el hombre, la conciencia, que no es la menos importantes, muy por el contrario es de vital importancia en la reflexión antropológica, es abordada explícitamente tan solo en el numeral 16.

\section{a. Conciencia: "hacer el bien y evitar el mal"}

Uno de los avances que pretendió la reflexión moral y ética del concilio, fue el superar el método y el enfoque casuístico que hasta entonces preponderaba en la moral cristiana, optándose por un enfoque personalista, donde "el punto de arranque será el hombre como ser creado a imagen y semejanza de Dios, redimido en Cristo e invitado a la plenitud de la vida en Él" (Morales, 2011, p. 101) Así pues, es precisamente como consecuencia de una pretensión personalista de la valoración e interpretación moral y ética del mundo, que superándose el uso de manuales, se apela a la conciencia como máxima de conducta y se constituye como el núcleo más secreto y el sagrario del hombre, en el que éste se siente a solas con Dios (GS 16.).

De este modo, siendo la conciencia el lugar privilegiado en donde el encuentro con Dios en intimidad sucede, es pues, también la receptora de la verdad descubierta por la luz de la razón y que "cernida" por ella, permite descubrir la voluntad de Dios manifiesta en la ley divina, evidente en el mundo, razón por la cual, en el n. 16 de la GS se explicita que es "en la profundidad de su conciencia descubre el hombre una ley que no se dicta él a sí mismo pero a la que debe obedecer y cuya voz suena con claridad a los oídos del corazón cuando conviene, invitándole siempre con voz suave a amar y a obrar el bien y evitar el mal." Por otra parte, el discernir la ley divina -captada por la razón-, vislumbrándose así la voluntad de Dios en el ejercicio recto y prudente de una conciencia formada en la búsqueda y adhesión de la verdad, necesariamente conlleva al recto juicio en diversos campos de la vida humana, como lo es, por ejemplo, la decisión de los padres en la elección del número de hijos, según lo expuesto en la GS n. 87; y en el discernir, juzgar y obrar en pro del bien común (GS n. 26) 
Así pues, en continuidad con los dos párrafos anteriores, y siguiendo lo expuesto en la constitución GS referente a la conciencia; una conciencia formada en la rectitud y la prudencia, como fruto de la búsqueda de la verdad y de la posterior adhesión a ella, constituida en "sagrario del hombre, donde tiene sus citas a solas con Dios, cuya voz resuena en el interior" (GS n. 16) será la norma de conducta, de valoración y de juicio moral, en conformidad con la ley divina, que contemplada y "rumiada" en la conciencia, dará por resultado el vislumbrar la voluntad de Dios. De este modo, es constitutivo de la dignidad de la personal la facultad de obrar según la propia conciencia. Esta realidad ontológica el concilio lo expresa afirmando que toda persona tiene "derecho a obrar según la recta norma de su conciencia." (GS n. 26)

De todo lo anterior se deduce que la conciencia no crea para sí una ley moral, ni el hombre se da a sí mismo una norma de comportamiento o máxima de moralidad; muy por el contrario, la conciencia es el recinto íntimo en donde las normas objetivas dadas por Dios en la ley natural, esto es, la verdad -que es captada por la razón y la inteligencia, y que junto con la voluntad mueven a adherirse a ella- reposa y comportan el descubrir la voluntad de Dios, motor de la conciencia moral.

De este modo, afirma el Papa Pio XII: "la conciencia es la voz de Dios en el santuario del hombre" (Pio XII, radiomensaje, (23-III-1952). (AAS (1952)272))

\section{b. Conciencia: "deber de amar"}

A partir de una lectura atenta del n. 16 de la Gaudium et Spes, se advierte que la conciencia no sólo pretende mover al Ser a "obrar el bien y evitar el mal", sino que también, y de manera primordial y categórica, debe ser expresión de caridad; en otras palabras, la conciencia además de ser "cernidor" en la que se desentraña lo bueno y lo malo a la luz de la voluntad Divina, es el campo donde Dios siembra la semilla de la vocación a una vida en la caridad, y dónde ésta debe dar frutos.

No se trata de ordenar axiológicamente que "deber" está primero, si el deber de obrar el bien y evitar el mal, o el deber de amar. Por el contario, es preciso vislumbrar que la conciencia -en la que reposa la verdad de la voluntad de Dios presente en la ley natural captada por la razón, e inscrita en el corazón del hombre- tiene su expresión máxima en la caridad, puesto que es en el amor a Dios y al prójimo que se planifica y consuma la verdad ontológica del Ser de ser hijos de Dios, creaturas hechas a imagen y semejanza de Dios, que es amor. Y es en la vida en la caridad -semejante al amor de Dios- que se plenifica la dignidad del 
hombre y se ahonda en la configuración con la imagen de Dios; Del mismo modo, según Santo Tomás, la imagen y la semejanza a Dios le vienen al hombre por su inteligencia y voluntad, por tanto, entre más dispuestas estén estas facultades ontológicas del ser a la caridad, se plenificará la dignidad del Ser como creatura e hijo de Dios.

Por otra parte, ¿de qué serviría percibir y descubrir por uso de la razón, la verdad de una ley natural, si se desconoce a Dios, y por tanto, no se ama, y en virtud de este amor, no se ama tampoco al prójimo?, ¿qué movería entonces a obrar bien y evitar el mal de sí mismos, y de los demás? En la vida del creyente, es precisamente el amor a Dios, y en virtud de éste, el amor a los demás, al prójimo, el motor que incita y mueve a actuar según la verdad de la voluntad de Dios percibida y captada por la inteligencia en la ley natural, y que por voluntad esa Verdad resguardada y discernida en la conciencia se expresa en la caridad. Es precisamente por el hecho de que en la conciencia convergen y se conjugan todas las facultades que nos configuran como creaturas constituidas a imagen y semejanza de Dios, que la conciencia es el "lugar" donde se da el contacto íntimo y personal con Dios y donde cuya voz resuena.

"Estas normas objetivas que todo hombre percibe en su conciencia, tiene, para el cristiano, su expresión máxima en la caridad (Mt 22, 33-40; Gal. 5, 14), la cual se explica porque el cristiano está en relación con el 'pneuma divino' por medio del cual se nos revela el amor de Dios y se suscita en nosotros una respuesta de amor" (Restrepo, 1993, p. 88)

Nuestra relación personal con Dios, se funda en la capacidad (razón) de conocerle y en la voluntad de amarle. Es precisamente que percatándose de la existencia de Dios y de la comunicación de su voluntad a través de una ley por la inteligencia, por la voluntad se orienta a Dios como su fin, en respuesta de amor al amor de Dios. Así pues, si por la razón se capta la verdad de Dios inscrita en el corazón del hombre, por la voluntad se orienta el ser en amor a Dios y al cumplimiento de su voluntad, ya que el solo conocer no es garante del actuar y del buen obrar, por lo cual, según Restrepo", "el amor es el principio rector de la conciencia" (1993, p. 88)

6 Gonzalo Restrepo Restrepo, Arzobispo de la Arquidiócesis de Manizales, Licenciado en Teología Fundamental de la Pontificia Universidad Gregoriana. 


\section{Catecismo de la Iglesia Catolica?}

No es sorprendente descubrir que el catecismo abra el artículo sexto "la conciencia moral" del capítulo primero: "La dignidad de la persona humana", (capitulo primero de la primera sección -"la vocación del hombre: la vida en el Espíritu"de la tercera parte del catecismo -“La vida en Cristo") con las palabras del Concilio Vaticano II consignadas en la constitución pastoral Gaudium Et Spes.

Sin embargo, añade diversos matices a la hora de abordar y tratar el tema de la conciencia. Así pues, el Catecismo enseña que la conciencia ejerce una tripartita misión en la vida del creyente, respecto a su dignidad, a saber: la misión de ordenar, juzgar y atestiguar. De este modo, la conciencia (conciencia moral) ordena al creyente direccionar sus acción hacia el bien, procurando no cometer error ni pecado; respecto del juzgar, la conciencia debe juzgar las actuaciones ya ocurridas y los hechos ya acontecidos con el ánimo de aprobar las buenas y denunciar las dañinas o perjudiciales; y por último, la conciencia debe cumplir con la misión de atestiguar la verdad divina que se haya en la opción por el bien supremo de actuar según la voluntad de Dios presente y evidente en la creación y en la ley.

"La conciencia moral le ordena, en el momento oportuno, practicar el bien y evitar el mal. Juzga también las opciones concretas aprobando las que son buenas y denunciando las que son malas. Atestigua la autoridad de la verdad con referencia al Bien supremo por el cual la persona humana se siente atraída y cuyos mandamientos acoge." (CEC, 1776)

Del mismo modo, el catecismo afirma que el conocer las prescripciones de la ley divina -ley natural y Revelación- obliga y ordena al hombre a obrar recta y justamente en todo lo que dice y hace, y esta ordenación se suscita en la conciencia. Sin embargo, para que la conciencia pueda ejercer plenamente su papel como "voz de Dios que resuena en el interior", existe una exigencia primordial, y esta es la interiorización. "Esta exigencia de interioridad es tanto más necesaria cuanto que la vida nos impulsa con frecuencia a prescindir de toda reflexión, examen o interiorización" (CEC, 1779) Si se vive el día a día con sus afanes, sin prestar atención, es difícil y casi que imposible percibir el querer de Dios evidente en el orden natural creación, en la ley divina; por tanto, la conciencia no será otra cosa que el "carrito de batalla" y de manipulación de ideologías e intereses.

7 Texto donde se compilan las verdades de fe en materia de doctrina, dogma y magisterio, que deben ser enseñadas con el propósito de conservar el depósito de la fe 
Ahora bien, el catecismo explicita las pautas necesarias para hacer de la conciencia la "rectora" del comportamiento y de las decisiones, a la vez que garante de una vida conforme a la dignidad humana; de este modo, siguiendo el 1780 del CEC, se pone de manifiesto que la rectitud de la conciencia moral comprende "la percepción de los principios de moralidad (Sindéresis), su aplicación a las circunstancias concretas mediante un discernimiento práctico de las razones y de los bienes, y en definitiva el juicio formado sobre los actos concretos que se van a realizar o se han realizado." Así pues, cumplido con el descrito derrotero, es posible determinar con justicia, rectitud y prudencia la bondad o maleficencia de un acto cumplido, de un acto a llevarse a cabo, de intenciones y decisiones, conforme a la dignidad humana, moldeada en una vida plena como creaturas hechas a imagen y semejanza de Dios, a la vez que como sus hijos. Ya que la recta conciencia está volcada y ordenada a posibilitar la vida plena en la dignidad de hijos de Dios, el Catecismo manda que nadie "debe ser obligado a actuar contra su conciencia. $\mathrm{Ni}$ se le debe impedir que actúe según su conciencia." (CEC, 1782)

¿De dónde nos viene una conciencia recta y prudente, o una conciencia errónea? Vista la importancia de la conciencia, la pregunta por el ¿De dónde nos viene? $\mathrm{O}$ ¿cómo llegar a una recta conciencia? es válida y necesaria. A este interrogante responde el CEC afirmando que la conciencia debe ser formada; es decir, la conciencia recta y justa no es algo que nos llegue en plenitud por efusión, sino que es una virtud que se cultiva con la formación. Si bien es cierto que todo ser humano por ser tal, (realidad ontológica) posee una conciencia, también lo es que una conciencia recta, justa y prudente sólo es posible con la formación que se suscita durante todo el tiempo de la existencia. Así pues, una conciencia formada de una que no lo está, se diferencian en que la primera "formula sus juicios según la razón, conforme al bien verdadero querido por la sabiduría del creador." (CEC, 1783), mientras que la segunda es esclava de los deseos personales, caprichos e intenciones del individuo. Respecto a una conciencia formada, enseña el catecismo:

“la educación de la conciencia es una tarea de toda la vida. Desde los primeros años despierta al niño al conocimiento de una ley interior reconocida por la conciencia moral. Una educación prudente enseña la virtud; preserva o sana del miedo, del egoísmo y del orgullo, de los insanos sentimientos de culpabilidad y de los movimientos de complacencia nacidos de la debilidad y de las faltas humanas. La educación de la conciencia garantiza la libertad y engendra la paz del corazón" (CEC, 1784)

\section{Universidad Santo Tomás, Facultad de Teología}


Ahora bien, tratándose de la conciencia del "núcleo recóndito, como un sagrario dentro del hombre, donde tiene sus citas a solas con Dios, cuya voz resuena en el interior" (GS n. 16), es indispensable la escucha atenta y constante de la Palabra de Dios en el arduo y duradero proceso de la formación de la conciencia. Si la conciencia es pues, el "lugar" donde se discierne la voluntad de Dios percibida en la ley divina, entonces es de apremiante necesidad escuchar y conocer la voluntad de Dios manifestada en Jesucristo, y a través del Él, el querer de Dios para toda la creación; por tanto, la conciencia recta y justa a de forjarse en la lectura constante, atenta y dedicada de la Palabra de Dios. En palabras del Catecismo, "en la formación de la conciencia. La Palabra de Dios es la luz de nuestro caminar; es preciso que la asimilemos en la fe y la oración, y la pongamos en práctica." (\# 1785), así mismo, la asistencia constante del Espíritu Santo con sus dones, el testimonio y consejo de los otros y la guía y enseñanza de la Iglesia son garantes de una formación prudente de la conciencia.

\section{Magisterio de S. S. Francisco ${ }^{8}$ y la conciencia}

Con la elección del Papa Francisco, se plantearon para la Iglesia Católica diversos retos en diferentes esferas y ámbitos de la vida de la Iglesia. Es el primer Cardenal no Europea que llega a la cátedra de San Pedro, lo que supone un modo de entender el mundo y la Iglesia -sus problemas, dificultades y carencias- distinto, con un plus fijo en la realidad social. El Papa Francisco representa para el mundo y para la Iglesia no sólo ojos distintos que observan y analizan el mundo y la Iglesia, sino que es un nuevo enfoque que llega a la Iglesia. No se trata de observar con ojos distintos la luz reflejada después de pasar por el prisma, se trata de darle un giro al prisma, darle un nuevo enfoque.

Otro aspecto importante que llama la atención, es el hecho de que por no tratarse de un Cardenal Europeo, la Iglesia percibe una discontinuidad en la tradición tanto eclesial como teológica eurocéntrica presente hasta entonces en la dirección de la Iglesia de Cristo; De este modo, la elección de un sudamericano representa una tradición eclesial y teológica distinta, con preocupaciones y realidades diferentes en el centro de su reflexión. Es precisamente por esta diversidad de realidades, de preocupaciones, de tradición eclesial y teológica, que el Papa

8 Cardenal Argentino Jorge Mario Bergoglio, elegido Sumo Pontífice (Papa número 266) de la Iglesia Católica el 13 de Marzo del 2013. 
Francisco representa novedad y desafío para la Iglesia. Esta es la razón por la cual, ante un tema de vasta importancia, como lo es la conciencia, el contraste entre la Iglesia del Concilio Vaticano II y el nuevo Magisterio es el objeto de estudio del presente artículo.

¿Cuál es la noción, la importancia, lo fundamental de la conciencia en el Papa Francisco? ¿Representa la concepción de conciencia del Papa Francisco novedad ante la doctrina expuesta hasta ahora -Concilio Vaticano II y Catecismo-? O por el contrario el magisterio de SS. Francisco representa continuidad con lo expuesto por la Iglesia del Concilio.

La pregunta por la concepción de conciencia en el Papa Francisco, no responde a una curiosidad de hacer notar una contradicción, adicionamiento o ratificación respecto de lo enseñado por la Iglesia en materia de conciencia (conciencia moral.), responde más bien a la intención de vislumbrar el desarrollo en materia de moral -en la que se haya inmiscuida la conciencia- que llega a SS Francisco y que éste asimila, aprehende y comunica a la Iglesia como Sumo Pontífice.

\section{a. Entrevistas, cartas y pronunciamientos varios.}

La Iglesia desde el pontificado de Juan Pablo II y Benedicto XVI ha enfocado su reflexión teológica en dos aspectos de la vida cristiana de fundamental importancia, a saber: la espiritualidad y la moral. En Palabras de José Manuel Vidal": "Se insistía tanto en la vertiente espiritual del cristianismo que se olvidaba el otro palo de la cruz, el símbolo de la fe, que es el temporalismo o el compromiso con los pobres. Se subrayaba tanto la defensa a ultranza de la moral sexual, que se convirtió en una obsesión, como reconoce el propio Papa-Francisco-, desvirtuándola hasta caer en el moralismo." (Vidal, 2013)

Según la denuncia hecha por Vidal, se deduce que en los tiempos pos conciliares, en vez de percibirse una moral liberadora, donde la conciencia jugara el papel primordial y fuera la rectora primera de la moral, se descubre que la fuerza de la autoridad ha transformado a la conciencia en vasallo del moralismo; esto es, la moralidad y el discernimiento de la voluntad de Dios que mueve y ordena a amar, al bien obrar y evitar el mal ya no haya su seno en la conciencia, sino en la autoridad que le viene de fuera.

9 Periodista y teólogo Español, experto en asuntos del Vaticano, Director del portal web periodístico "religión digital". Coautor del primer libro sobre el Papa Francisco titulado: "Francisco: el nuevo Juan XXIII". 
Siguiendo a Vidal, muestra de lo anteriormente expuesto, es el hecho de que tres grandes moralista de la Iglesia hayan sido blanco de persecuciones, denuncias y desprestigios por parte de algunas autoridades jerárquicas de la Iglesia y del ex santo oficio, a saber, Benjamín Forcano, Marciano Vidal y Bernard Häring.

"Forcano es un claretiano que sufrió un proceso extraordinario por parte de las autoridades romanas a raíz de la publicación de su libro ‘Nueva Ética Sexual' en 1981. (...) El redentorista Marciano Vidal también fue llamado al orden por Roma por sus enseñanzas morales en 2001. Y hasta se prohibió que su gran obra teológica "Moral de actitudes" se utilizase como manual en los seminarios. (...) El padre de todos los moralistas, el alemán Bernard Häring, corrió una suerte parecida: Sufrió mucho, le calumniaron si piedad y le sometieron a un duro proceso ante el ex Santo Oficio. Sostenía que, en cuestiones de moral, la conciencia siempre prevalece sobre la ley." (Vidal, 2013)

Según lo advierte Vidal, uno de los primeros esfuerzos del Papa Francisco fue el recuperar a los moralistas que han sido calificados de inapropiados para la enseñanza por su doctrina en materia de moral y de conciencia. En Palabras de Vidal, "-El Papa Francisco- Quiere que la Iglesia vuelva a la moral de actitudes y a la primacía de la conciencia." (Vidal, 2013)

Según se logra entrever en las declaraciones ofrecidas por el Papa en la entrevista citada por Vidal, es evidente la intención del Sumo Pontífice de apostarle en el campo de la moral, a una primacía de la conciencia por encima del moralismo tan marcado y presente en las décadas anteriores de su elección. S. S. Francisco, por encima de la ley ubica a la conciencia del Ser; de este modo, es obediente y trae al siglo XXI las palabras del concilio y les da vida: "el hombre tiene el derecho de actuar en conciencia y en libertad a fin de tomar personalmente las decisiones morales. -no debe ser obligado a actuar contra su conciencia." (DH n. 3).

Por otra parte, en la entrevista al Papa Francisco concedida al Sacerdote Jesuita Antonio Spadaro, S. J. ${ }^{10}$ El sumo Pontífice esclarece que si bien es cierto la Iglesia posee y dispone de doctrinas generales que direccionen y ordenan cada aspecto de la vida del ser humano para hacerlo agradable ante los ojos de Dios, también lo es que cada situación debe abordarse con misericordia y caridad en la práctica pastoral. Es decir, ante una dialéctica entre la norma prescrita en la doctrina, y la misericordia y la caridad en la pastoral, debe propenderse siempre

10 Sacerdote Jesuita director de la revista La Civiltà Cattolica. 
por el equilibro; pero ante el equilibrio, la conciencia del Ser debe ubicarse por encima de la norma. Así pues, en Palabras del Papa Francisco:

“Las enseñanzas de la Iglesia, sean dogmáticas o morales, no son todas equivalentes. Una pastoral misionera no se obsesiona por transmitir de modo desestructurado un conjunto de doctrinas para imponerlas insistentemente. El anuncio misionero se concentra en lo esencial, en lo necesario, que, por otra parte es lo que más apasiona y atrae, es lo que hace arder el corazón, como a los discípulos de Emaús.

Tenemos por tanto que encontrar un equilibrio, porque de otra manera el edificio moral de la Iglesia corre peligro de caer como un castillo de naipes, de perder la frescura y el perfume del Evangelio. La propuesta Evangélica debe ser más sencilla, más profunda e irradiante. Solo de esta propuesta surgen luego las consecuencias morales." (Spadaro, 2013, p. 15)

En otro pronunciamiento del Sumo Pontífice, esta vez, en una carta dirigida al Eugenio Scalfari (fundador del diario italiano -la república-), SS Francisco pone de manifiesto varios aspectos importante en cuanto a la conciencia se refiere. De este modo, ante el interrogante suscitado por Scalfari sobre ¿cuál sería la relación de Dios -y por ende, la relación de la salvación- con el que no cree y no tiene fe? El Papa Francisco responde afirmando que "Si acudimos a Él (Dios) con corazón sincero y contrito, la cuestión para quien no cree está en obedecer a la propia conciencia. (...) Escucharla y obedecerla significa, de hecho, decidirse frente a lo que se percibe como bueno o como malo. Y en esta decisión se juega la bondad o la maldad de nuestras acciones." (S. S. Francisco, 2013a)

El ser humano, por sus facultades de inteligencia y razón descubre y aprehende para sí lo que es bueno y lo que es malo conforme a una ley moral natural que se percibe y se evidencia en la ley natural. El creyente descubre en tal ley natural y por ende, en tal ley moral natural la mano y el querer de Dios y rige por tanto su comportamiento a este querer, conforme también a la revelación que le orienta hacia Dios; pero el no creyente, por esta misma razón e inteligencia descubre en la ley moral natural una máxima de comportamiento y de ordenación de la propia vida, que aunque alejado de Dios, le conduce a discernir en su conciencia la bondad en el decir y el hacer, por tanto busca y pretende la bondad, y ya que Dios es la bondad suprema, encontrará el camino que le llevará a encontrarse con Dios.

La conciencia del no creyente será recta y justa, en tanto que no sea obediente a las pasiones, intereses personales y deseos propios del individuo; será, 
pues, recta y justa en tanto que, aunque alejada de Dios, sea obediente a la verdad inmersa y presente en la ley moral natural; de este modo, la conciencia del no creyente será conforme a la voluntad de Dios de manera parcial (pues en el conocimiento de Dios se encuentra el querer de Dios pleno) y le conducirá a Él.

"Al acoger la ley moral en nosotros, en un cierto sentido ya estamos acogiendo a Dios que es su autor. Esto exige a la conciencia, y también a la del no creyente, comprometerse a comprender hasta el fondo la riqueza de su conciencia." (Stefano Fontana, 2013.) ${ }^{11}$

\section{b. Exhortación Apostólica "Evangelii Gaudium”}

El Papa Francisco después de abrir su exhortación apostólica Evangelii Gaudium (EG) anunciando la alegría que trae consigo el evangelio para quienes viven en un encuentro cotidiano con Cristo, denuncia el riesgo en el que se encuentra el mundo actual a raíz de las consecuencias de una "abrumadora oferta de consumo". (Francisco, 2013b, n. 2) Entre las múltiples y devastadoras consecuencias, el Papa denuncia "una conciencia aislada". (2013b, n. 2)

¿Cómo una conciencia puede a ser capaz de percibir y descubrir la verdad en la ley moral natural presente en la ley divina regente del cosmos, si el individuo sólo se preocupa de satisfacer sus intereses y caprichos, olvidándose totalmente del otro?

Es en la orientación natural del Ser al Bien y en la búsqueda de su perfeccionamiento, en donde la conciencia se encuentra con la verdad y escucha la voz de Dios, lo cual es imposible si el otro no existe, puesto que es el amor al otro lo que orienta la conciencia moral al bien suyo y al propio. Si el individuo no centra su atención en el percibir y descubrir la voluntad y el amor de Dios en el cosmos que le rodea y en las personas que tiene a su lado, su conciencia no estará conectada a la verdad ni estará orientada a la consecución del Bien, por tanto no discernirá lo bueno de lo malo; su conciencia estará aislada. Así pues, "cuando la vida interior se clausura en los propios intereses, ya no hay espacio para los demás, ya no entran los pobres, ya no se escucha la voz de Dios, ya no se goza la dulce alegría de su amor, ya no palpita el entusiasmo por hacer el bien." (2013b, n. 2)

11 Texto recuperado de http://www.vanthuanobservatory.org/notizie-dsc/notizia-dsc. php?lang=es\&id $=1735$ 
¿Cómo rescatar a la conciencia de caer en el aislamiento? Según sigue Francisco en su exhortación, el camino para liberar a la conciencia del aislamiento es el encuentro personal con Cristo. Puesto que no se decide a amar, a obrar el bien y evitar el mal para luego emprender la búsqueda de la verdad, sino que el proceso es totalmente contrario, primero se suscita el encuentro con la verdad y la posterior adición a ella por inteligencia y voluntad, para a continuación orientar la vida según la Verdad. Así pues, es el encuentro con Cristo lo que mueve al correcto y buen obrar, a un discernimiento de lo bueno y lo malo a la luz de la verdad que en Él se manifiesta. "Sólo gracias a ese encuentro - o reencuentro- con el amor de Dios, que se convierte en feliz amistad, somos rescatados de nuestra conciencia aislada y de la autorreferencialidad." (2013b, n. 8)

Ahora bien, además de ser el "lugar" donde se escucha la voz de Dios, la conciencia debe ser la primera en inquietarse por aquellos que Dios ha puesto a su alrededor. Siendo pues, la conciencia donde reposa y se discierne la verdad por Dios revelada y por la cual por su conomiento se orienta la vida y la voluntad al creador, la conciencia debe inquietarse por que los demás también lleguen al conocimiento de esa verdad, que no es otra que la verdad de Jesucristo y del amor y la voluntad de Dios en ÉL revelada. De este modo lo expresa el Papa Francisco: "Si algo debe inquietarnos santamente y preocupar nuestra conciencia, es que tantos hermanos nuestros vivan sin la fuerza, la luz y el consuelo de la amistad con Jesucristo, sin una comunidad de fe que los contenga, sin un horizonte de sentido y de vida." (2013b, 49)

La última referencia que sobre la conciencia hace el Papa Francisco en su Exhortación Apostólica, es sobre el papel que desempeña la conciencia en los que no creen en Cristo. Así pues, según SS Francisco, los no cristianos por una vida según la propia conciencia pueden vivir Justificados. No se trata de una conciencia cualquiera, o ajustada a los intereses propios y egoísta, como se ha dicho en párrafos atrás; se trata de una conciencia que bajo la exigencia de un discernimiento del bien obrar y de evitar el mal, que busque la verdad del Bien para sí y para los demás, y por ende que considere a los demás como semejantes, dignos de respetar y de amar, será una conciencia que -a pesar de estar alejada de Dios- existiendo según la verdad de la ley moral natural, común para creyentes y no creyentes, conducirá para el Ser la justificación mediante la gracia de Dios, puesto que se existe -aunque no se sepa o pretenda- conforme a la ley divina. Así también, el existir constante conforme a la ley divina, conforme a la ley moral natural, conducirá tarde que temprano a su creador, al encuentro con el autor de la ley divina. En palabras del Papa Francisco: “Los no cristianos, por la gratuita iniciativa divina, y fieles a su conciencia, pueden vivir «justificados mediante la 
gracia de Dios», y así «asociados al misterio pascual de Jesucristo». Pero, debido a la dimensión sacramental de la gracia santificante, la acción divina en ellos tiende a producir signos, ritos, expresiones sagradas que a su vez acercan a otros a una experiencia comunitaria de camino hacia Dios." (2013b, n. 254)

\section{Conclusiones}

\section{a. ¿Continuidad?}

A modo de Conclusión, luego de un amplio y vasto abordaje sobre la conciencia en una doble vertiente, a saber, por una parte en los documentos conciliares, en especial en la declaración Dignitatis Humanae y en la constitución Gaudium et Spes, así como en el catecismo de la Iglesia Católica; Y por otra parte en el magisterio de SS Francisco, en especial en su Exhortación Apostólica Evangelii Gaudium, y en pronunciamientos varios como cartas y entrevistas, puede argüirse que en lo concerniente a la noción de conciencia, en cuanto significado, propósito, y exigencias de la misma, se percibe una continuidad.

\section{b. Concordancia}

El Concilio afirma que las facultades de inteligencia y voluntad inherentes al Ser del hombre que posibilitan el conocimiento de la verdad y direccionan las acciones al bien, constituyen al hombre en Ser moral, razón por la cual, en líneas del Concilio se afirma que "ésta dimensión moral es una estructura inherente a la naturaleza del hombre." (Braun, 1969, p. 42). En esta dirección apunta el Papa Francisco al afirmar que un no creyente debe obedecer a su conciencia, regir su vida y sus actos de acuerdo a ella, puesto que, aun estando alejado de Dios y de la verdad revelada en Cristo, su realidad ontológica como ser moral le es inherente. Así pues, el hombre, independientemente de su fe o no en Cristo, está llamado en virtud de su naturaleza a buscar el bien en el decir y el hacer, puesto que su inteligencia a ello le orienta. Ante esta realidad moral, el Papa Francisco explicita que "la cuestión para quien no cree está en obedecer a la propia conciencia. (...) Escucharla y obedecerla significa, de hecho, decidirse frente a lo que se percibe como bueno o como malo. Y en esta decisión se juega la bondad o la maldad de nuestras acciones." (SS. Francisco, 2013a)

Por otra parte, en la declaración $D H$ se expresa que "todos los hombres, conforme a su dignidad, por ser personas, es decir, dotados de razón y voluntad 
libre (...) tienen la obligación moral de buscar la verdad (...). Están obligados asimismo, a adherirse a la verdad conocida y a ordenar toda su vida según las exigencias de la verdad." (DH, p. 423). A lo cual, en continuidad con el Concilio, el Papa Francisco argumenta que el no creyente, por esta misma razón e inteligencia descubre en la ley moral natural una máxima de comportamiento y de ordenación de la propia vida, que aunque alejado de Dios, le conduce a discernir en su conciencia la bondad en el decir y el hacer. El no creyente aunque alejada de Dios, debe ser obediente a la verdad inmersa y presente en la ley moral natural;

“Al acoger la ley moral en nosotros, en un cierto sentido ya estamos acogiendo a Dios que es su autor. Esto exige a la conciencia, y también a la del no creyente, comprometerse a comprender hasta el fondo la riqueza de su conciencia." (Fontana, 2013)

Existe pues, un elemento común y fundamental en lo que refiere a la conciencia, tanto en el Concilio como en SS Francisco, esto es, la ley moral natural. $\mathrm{Al}$ respecto, el Concilio diserta que la ley moral el Ser no se la da así mismo, sino que le es dada por Dios. El ser por su razón conoce la ley natural, pero es en la conciencia donde el hombre descubre en ella la voluntad de Dios, voluntad a la que ha de ser obediente; por tanto, la ley natural, como ley querida por Dios para comunicar la verdad y la naturaleza del hombre en relación con la verdad de sí mismo, se transforma en máxima del comportamiento moral, de conciencia moral, para hacer el bien y evitar el mal. Ante lo expuesto por el concilio, SS Francisco argumenta, en concordancia, que es precisamente el encuentro con la verdad lo que orienta el comportamiento hacia el Bien supremo, convirtiéndose ésta en máxima de comportamiento, y no alcontrario; de este modo, no se decide a amar, a obrar el bien y evitar el mal para luego emprender la búsqueda de la verdad, sino que el proceso es contrario, primero se suscita el encuentro con la verdad y la posterior adición a ella por inteligencia y voluntad, para a continuación orientar la vida según la Verdad.

Se trata, pues, según SS Francisco, de una conciencia que bajo la exigencia de un discernimiento del bien obrar y de evitar el mal, que busque la verdad del Bien para sí y para los demás, sea una conciencia que -a pesar de estar alejada de Dios- existiendo según la verdad de la ley moral natural, común para creyentes y no creyentes, conducirá para el Ser la justificación mediante la gracia de Dios, puesto que se existe -aunque no se sepa o pretenda- conforme a la ley divina; además, la permanencia en una vida conforme a la ley moral natural, conducirá 
tarde que temprano a su creador, al encuentro con el autor de la ley divina. Así lo expresa SS Francisco:

"la acción divina en ellos tiende a producir signos, ritos, expresiones sagradas que a su vez acercan a otros a una experiencia comunitaria de camino hacia Dios." (2013b, n. 254)

Por otra parte, el Concilio, advierte que la conciencia no sólo pretende mover al Ser a "obrar el bien y evitar el mal", sino que también, y de manera primordial y categórica, debe ser expresión de caridad. ¿Qué movería entonces a obrar bien y evitar el mal de sí mismos, y de los demás? En la vida del creyente, es precisamente el amor a Dios, y en virtud de éste, el amor a los demás, al prójimo, el motor que incita y mueve a actuar según la verdad de la voluntad de Dios. Ante esta advertencia del concilio, el Papa Francisco, en continuidad, explicita que "cuando la vida interior se clausura en los propios intereses, ya no hay espacio para los demás, ya no entran los pobres, ya no se escucha la voz de Dios, ya no se goza la dulce alegría de su amor, ya no palpita el entusiasmo por hacer el bien." (2013, n. 2) Según SS Francisco, la preocupación por los otros debe nacer del amor, del amor a Dios y a los demás; ese mismo amor se traduce en la vida en entusiasmo de hacer el bien. Así pues, la conciencia debe ser la primera en inquietarse por aquellos que Dios ha puesto alrededor, y el amor debe inquietar a la conciencia porque los demás también lleguen al conocimiento de la Verdad, que no es otra que la verdad de Jesucristo y del amor y la voluntad de Dios en ÉL revelada.

Por último, es evidente después de este largo recorrido respecto de la conciencia en las enseñanzas de la Iglesia en el Concilio Vaticano II y en el magisterio de S. S. Francisco, que lo primordial y fundamental en la comprensión del papel e importancia de la conciencia, es la base antropológica. Así pues, lo que explica el porqué del acercamiento y convergencia entre las disertaciones del Concilio y las del Papa Francisco, respecto de la conciencia, es el hecho de una base antropológica común. En ambas líneas de reflexión “el punto de arranque será el hombre como ser creado a imagen y semejanza de Dios, redimido en Cristo e invitado a la plenitud de la vida en Él" (Morales, 2011, p. 101) de este modo, con la pretensión personalista de la antropología del Concilio y de SS Francisco en el acercamiento a la conciencia en la reflexión moral de la Iglesia, el primer y primordial paso es el apelar a la conciencia como máxima de conducta, constituyéndose ésta en "el núcleo más secreto y el sagrario del hombre, en el que éste se siente a solas con Dios" (GS n. 16.). 


\section{Referencias}

Alarcón, A. M. (2012). Breve síntesis de las constituciones del concilio vaticano II, Instituto Pastoral Apóstol Santiago. En: www.inpas.cl. Recuperado: 06 de octubre de 2014.

Biblia de Jerusalén (1967). Bilbao: Desclée De Brouwer.

Braun, R., (1969). El tema de la conciencia en los documentos recientes del Magisterio, Revista Teología, revista de la Facultad de Teología de la Pontificia Universidad Católica Argentina, ISSN 0328-1396, №. 14, págs. 41-50.

Concilio Vaticano II (1987). Documentos completos, Bogotá: Ediciones Paulinas.

Flecha, A., J. R., (2001). Teología Moral Fundamental, serie de manuales de teología. Madrid: BAC.

Fontana, S. (2013, 18 de noviembre) Lo absoluto y la conciencia en la carta del Papa Francisco a Eugenio Scalfari. Algunas observaciones, Periódico virtual Observatorio Internacional Cardenal Van Thuân. En: http://www.vanthuanobservatory.org/ notizie-dsc/notizia-dsc.php?lang=es\&id=1735. Recuperado: 20 de agosto de 2014 .

Juan Pablo II, (1992). Catecismo de la Iglesia Católica. Roma: Librería Editrice Vaticana, Edición en Español para la Conferencia Episcopal de Colombia.

Luño, Á. R. (2012, 5 de Diciembre). La Libertad, la ley y la conciencia, Portal web del Opus Dei. En: http://opusdei.es/es-es/article/tema-26-la-libertad-la-ley-y-la-conciencia/._Recuperado: 06 de julio de 2014.

Martínez, L. (2014). La Conciencia moral, Carta pastoral, Revista virtual Ecclesia. En: http://www.revistaecclesia.com/la-conciencia-moral-por-lluis-martinez-sistachcardenal-arzobispo-de-barcelona/. Recuperado: 30 de marzo de 2014.

Morales, L., G., A., (2011). Gaudium et Spes y la conciencia moral. Valoración y retos, Revista Iberoamericana de Teología, vol. VII, núm. 12, enero-junio. Ciudad de México: Universidad Iberoamericana. pp. 101-126.

Ratzinger, J., (1992). Conciencia y verdad. En: La Iglesia: una comunidad siempre en camino. Madrid: Ediciones Paulinas.

Restrepo, G. R. (1993). Lineas fundamentales de la antropología cristiana en la constitución pastoral Gaudium et Spes, Disertación para licenciatura en teología fundamental. Roma.

S. S. Francisco (2013b). Exhortación Apostólica Evengelii Gaudium, Librería Editrice Vaticana. Bogotá: Paulinas.

S. S. Francisco (2013a). Carta del Santo Padre Francisco al periodista italiano Eugenio Scalfari. En: http://w2.vatican.va/content/francesco/es/letters/2013/documents/papafrancesco_20130911_eugenio-scalfari.html. Recuperado: 04 de septiembre de 2014.

Spadaro, A. (2013). Entrevista al Papa Francisco, L'Osservatore Romano, edición semanal en lengua española, Año XLV, n. 39 (2.333). 